Editorial

\title{
The Potential of Cesarean Section as a Causative Factor of Chronic Pelvic Pain
}

\section{O potencial da cesárea como elemento causador de dor pélvica crônica}

\author{
Antonio Alberto Nogueira ${ }^{1}$ Júlio Cesar Rosa e Silva ${ }^{1}$ Omero Benedito Poli Neto ${ }^{1}$ \\ ${ }^{1}$ Gynecology and Obstetrics Department, Faculdade de Medicina de \\ Ribeirão Preto, Universidade de São Paulo, Ribeirão Preto, SP, Brazil \\ Rev Bras Ginec Obst 2016;38:53-55.
}

Chronic pelvic pain (CPP) is a prevalent condition among women, particularly those of reproductive age, estimated at around $4 \%{ }^{1}$ In Brazil, the prevalence data are lacking, but it may be higher than $10 \%^{2,3}$ The initial diagnosis is eminently clinical and, according to the International Association for the Study of Pain (IASP), it consists of chronic or persistent pain perceived in pelvis-related structures, often associated with emotional, sexual, behavioral, and negative cognitive consequences, as well as symptoms suggestive of disorders in these systems. It includes both cyclic pain, such as dysmenorrhea, and the acyclic type. Although six months is the most widely used time criterion, it is arbitrary and, if the pain is not typically acute and central sensitization mechanisms are well documented (especially hyperalgesia), it can be considered chronic, regardless of time of symptom onset.

Among the several risk factors attributed to $\mathrm{CPP}^{4}$ we highlight the history of prior abdominal surgery, particularly low transverse incision of the abdominal wall (Pfannenstiel), commonly used in cesarean sections (CS) and other gynecological surgeries..$^{5}$ Considering that CS is the most frequently performed abdominal surgery in the world ${ }^{6}$ and the fact that CS rates in Brazil are very high, ${ }^{7}$ it is known that many CPP cases can be attributed to CS. ${ }^{8}$

In clinical practice, many professionals, especially gynecologists and obstetricians, attribute the development of postoperative adhesions as the cause of pain. Moreover, they underestimate the diagnosis of pain originating in the abdominal wall, ${ }^{9}$ which is a confirmed cause of CPP, of simple treatment and a good response rate, preventing the need for surgical approach to clarify the diagnosis.

\section{CPP Originating in the Abdominal Wall}

Regarding abdominal wall pain, neuropathy and myofascial syndrome are some of the most important. The most com-

Address for correspondence DOI http://dx.doi.org/ Antonio Alberto Nogueira, MD, PhD, 10.1055/s-0036-1571850. Departamento de Ginecologia e ISSN $0100-7203$.

Obstetrícia, Av. Bandeirantes, 3900,

Ribeirão Preto, SP, Brazil 14049-900

(e-mail: aanoguei@fmrp.usp.br). mon neuropathies affect the iliohypogastric, ilioinguinal, and genitofemoral nerves. They are caused by nerve section (with neuroma formation or poor adaptive neuroplasticity), inadvertent nerve ligation or fibrous scarring of the surrounding tissue with nerve entrapment. ${ }^{10}$ The myofascial syndrome has a more obscure pathophysiology and is attributed to tissue ischemia due to prolonged muscle contraction and consequent accumulation of inflammatory substances such as serotonin, histamine, and prostaglandin. These substances have the ability to induce muscle contraction, which would generate a vicious reverberation cycle, even after cessation of the triggering event. ${ }^{11}$ Due to the similarities between them and the lack of consensus in the differential diagnosis, ${ }^{12}$ we will treat it as a single condition in this editorial.

It is primarily characterized by the presence of trigger points (TP) in the abdominal wall, although this does not necessarily exclude a visceral origin for the persistent pain. ${ }^{13,14}$ Such TP are defined as small areas of intense hyperalgesia located in a region of skeletal muscle or fascia (rectus abdominis and external oblique muscles, most commonly) which, when compressed, cause the abovementioned pain (in the corresponding dermatome or in a distant one), with or without perceived contracture of the local muscles and/or autonomic changes in the underlying skin, such as piloerection or sweating. ${ }^{15}$ Although it is not part of the routine physical examination by the gynecologist/obstetrician, the TP can be easily identified by trained observers. ${ }^{16}$ Alterations in sensitivity (hypoesthesia, anesthesia, dysesthesia) on the skin adjacent to the TP is frequently observed.

TP confirmation is basically attained with the injection of a small amount of local anesthetic without a vasoconstrictor agent, which should result in immediate pain relief. Treatment consists in maintaining local injections ${ }^{17,18}$ at different intervals. Significant symptom relief is $\sim 80 \%$ and persists for

Copyright $\odot 2016$ by Thieme Publicações License terms Ltda, Rio de Janeiro, Brazil

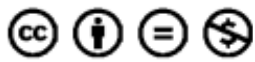


at least three months. ${ }^{19}$ Complementary laboratory tests are not essential, but a transvaginal pelvic and abdominal wall ultrasound is recommended mainly to exclude an eventual diagnosis of hernia and/or endometrioma. When symptomatic relief is transitory, and especially if there are signs of neuropathic pain, the concomitant use of drugs such as antidepressants (amitriptyline, duloxetine) and/or anticonvulsants (carbamazepine, pregabalin, gabapentin) is recommended. ${ }^{20}$ It is important to remember that, if the pain is typically neuropathic, there is no indication for the use of nonsteroidal anti-inflammatory drugs. ${ }^{21}$

For the group of women who do not improve with the abovementioned treatment, a laparoscopy is recommended. This is due to the fact that, at least in our experience, some of them have dense adhesion of viscera to the abdominal wall. We will further discuss the association between CPP and adhesions below, but evidence suggests that this particular type of adhesion is more consistently associated with CPP. ${ }^{22}$

\section{CPP Originating in Peritoneal Adhesions}

Regarding adhesions, the data are less clear. On the one hand, we know that any abdominopelvic surgery is capable of triggering a series of molecular and biochemical events in the peritoneal cavity that can usually culminate in the development of adhesions ${ }^{23}$ and, unfortunately, to date there is no effective method to prevent adhesion formation. Regarding the $\mathrm{CS},{ }^{24}$ it is presumed that the occurrence of adhesions ranges from 12 to $46 \%$ and 26 to $75 \%$, respectively, after two or three procedures. ${ }^{25}$ The exact proportion of the cases that will progress to CPP remains unknown. What is known is that, among patients with persistent abdominal and/or pelvic pain, the laparoscopy identifies adhesions in 15 to $40 \%$ of cases. ${ }^{26,27}$ The fact is that in spite of these findings, there is not enough data in the literature to attribute a causal association between the presence of adhesions and CPP onset. ${ }^{28}$

Is it reasonable to justify the pain as a symptom secondary to adhesions? Yes, but probably not too simplistically. Studies have shown the presence of sensory nerve fibers in peritoneal adhesions, both myelinated and non-myelinated fibers, associated with the presence of blood vessels, but distributed in a manner that is irrespective of the site, morphological characteristics, or even the presence of pain. ${ }^{29}$

Taking such probability into account, most services recommend adhesiolysis when adhesions are identified. However, a recent literature review does not convincingly support that adhesiolysis is enough to improve abdominal and/or pelvic pain. ${ }^{30}$ Based on many controversial and inconclusive data, we can only deduce that there is a complexity not yet disclosed on the role of peritoneal adhesion in the genesis of CPP.

\section{Final Considerations}

CS, especially if repeated, is a surgical procedure with potential to cause chronic pelvic pain, which is another reason to avoid its indiscriminate use. When indicated, the use of the best possible surgical technique is the only known method that can prevent damage to the nerves or myofascial elements of the abdominal wall and minimize the risk of peritoneal adhesion formation. These are the potential causes of symptoms.

A detailed clinical history and physical examination is able to direct the diagnosis and support the initial therapeutic approach. Abdominal wall involvement is the most common condition and, therefore, the indication for laparoscopy is justifiable only when the presence of trigger points has been ruled out or when the initial therapy does not have the desired effect. Additionally, there is no recommendation for nonsteroidal anti-inflammatory drug prescription for women whose pain is typically neuropathic.

\section{References}

1 Latthe P, Latthe M, Say L, Gülmezoglu M, Khan KS. WHO systematic review of prevalence of chronic pelvic pain: a neglected reproductive health morbidity. BMC Public Health 2006;6:177

2 Silva GPOG, Nascimento AL, Michelazzo D, et al. High prevalence of chronic pelvic pain in women in Ribeirão Preto, Brazil and direct association with abdominal surgery. Clinics (Sao Paulo) 2011;66(8):1307-1312

3 Coelho LS, Brito LM, Chein MB, et al. Prevalence and conditions associated with chronic pelvic pain in women from São Luís, Brazil. Braz J Med Biol Res 2014;47(9):818-825

4 Latthe P, Mignini L, Gray R, Hills R, Khan K. Factors predisposing women to chronic pelvic pain: systematic review. BMJ 2006; 332(7544):749-755

5 Loos MJ, Scheltinga MR, Mulders LG, Roumen RM. The Pfannenstiel incision as a source of chronic pain. Obstet Gynecol 2008; 111(4):839-846

6 Gibbons L, Belizan JM, Lauer JA, Betran AP, Merialdi M, Althabe F. Inequities in the use of cesarean section deliveries in the world. Am J Obstet Gynecol 2012;206(4):331.e1-331.e19

7 Ribeiro VS, Figueiredo FP, Silva AA, et al. Why are the rates of cesarean section in Brazil higher in more developed cities than in less developed ones? Braz J Med Biol Res 2007;40(9): $1211-1220$

8 Almeida EC, Nogueira AA, Candido dos Reis FJ, Rosa e Silva JC. Cesarean section as a cause of chronic pelvic pain. Int J Gynaecol Obstet 2002;79(2):101-104

9 Montenegro ML, Gomide LB, Mateus-Vasconcelos EL, et al. Abdominal myofascial pain syndrome must be considered in the differential diagnosis of chronic pelvic pain. Eur J Obstet Gynecol Reprod Biol 2009;147(1):21-24

10 Perry CP. Peripheral neuropathies and pelvic pain: diagnosis and management. Clin Obstet Gynecol 2003;46(4):789-796

11 Partanen JV, Ojala TA, Arokoski JP. Myofascial syndrome and pain: A neurophysiological approach. Pathophysiology 2010;17(1):19-28

12 Lindsetmo RO, Stulberg J. Chronic abdominal wall pain-a diagnostic challenge for the surgeon. Am J Surg 2009;198(1):129-134

13 Jarrell J. Endometriosis and abdominal myofascial pain in adults and adolescents. Curr Pain Headache Rep 2011;15(5):368-376

14 Jarrell J, Giamberardino MA, Robert M, Nasr-Esfahani M. Bedside testing for chronic pelvic pain: discriminating visceral from somatic pain. Pain Res Treat 2011;2011:692102

15 Simons DG. The nature of myofascial trigger points. Clin J Pain 1995;11(1):83-84

16 Tough EA, White AR, Richards S, Campbell J. Variability of criteria used to diagnose myofascial trigger point pain syndrome-evidence from a review of the literature. Clin J Pain 2007;23(3):278-286 
17 Ling FW, Slocumb JC. Use of trigger point injections in chronic pelvic pain. Obstet Gynecol Clin North Am 1993;20(4):809-815

18 Iwama H, Akama Y. The superiority of water-diluted $0.25 \%$ to neat $1 \%$ lidocaine for trigger-point injections in myofascial pain syndrome: a prospective, randomized, double-blinded trial. Anesth Analg 2000;91(2):408-409

19 Montenegro MLLS, Braz CA, Rosa-e-Silva JC, Candido-dos-Reis FJ, Nogueira AA, Poli-Neto OB. Anaesthetic injection versus ischemic compression for the pain relief of abdominal wall trigger points in women with chronic pelvic pain. BMC Anesthesiol 2015; $15: 175$

20 Ney JP, Devine EB, Watanabe JH, Sullivan SD. Comparative efficacy of oral pharmaceuticals for the treatment of chronic peripheral neuropathic pain: meta-analysis and indirect treatment comparisons. Pain Med 2013;14(5):706-719

21 Vo T, Rice AS, Dworkin RH. Non-steroidal anti-inflammatory drugs for neuropathic pain: how do we explain continued widespread use? Pain 2009;143(3):169-171

22 Mettler L, Alhujeily M. Role of laparoscopy in identifying the clinical significance and cause of adhesions and chronic pelvic pain: a retrospective review at the Kiel School of Gynecological Endoscopy. JSLS 2007;11(3):303-308
23 Imudia AN, Kumar S, Saed GM, Diamond MP. Pathogenesis of Intra-abdominal and pelvic adhesion development. Semin Reprod Med 2008;26(4):289-297

24 Lauder CI, Garcea G, Strickland A, Maddern GJ. Abdominal adhesion prevention: still a sticky subject? Dig Surg 2010;27(5):347-358

25 Walfisch A, Beloosesky R, Shrim A, Hallak M. Adhesion prevention after cesarean delivery: evidence, and lack of it. Am J Obstet Gynecol 2014;211(5):446-452

26 Sharma D, Dahiya K, Duhan N, Bansal R. Diagnostic laparoscopy in chronic pelvic pain. Arch Gynecol Obstet 2011;283(2):295-297

27 Husain M, Sachan PK, Khan S, Lama L, Khan RN. Role of diagnostic laparoscopy in chronic and recurrent abdominal pain. Trop Gastroenterol 2013;34(3):170-173

28 ACOG Committee on Practice Bulletins-Gynecology. ACOG Practice Bulletin No. 51. Chronic pelvic pain. Obstet Gynecol 2004; 103(3):589-605

29 Sulaiman H, Gabella G, Davis MSc C, et al. Presence and distribution of sensory nerve fibers in human peritoneal adhesions. Ann Surg 2001;234(2):256-261

30 Gerner-Rasmussen J, Burcharth J, Gögenur I. The efficacy of adhesiolysis on chronic abdominal pain: a systematic review. Langenbecks Arch Surg 2015;400(5):567-576 